\title{
Hybrid genotypes in the pathogenic yeast Cryptococcus neoformans
}

\author{
Teun Boekhout, ${ }^{1}$ Bart Theelen, ${ }^{1}$ Mara Diaz, ${ }^{2}$ Jack W. Fell, ${ }^{2}$ \\ Wim C. J. Hop, ${ }^{3}$ Edwin C. A. Abeln, ${ }^{1}$ Françoise Dromer ${ }^{4}$ \\ and Wieland Meyer ${ }^{5}$
}

Author for correspondence: Teun Boekhout. Tel: +31 30 2122671. Fax: +31 302512097.

e-mail: boekhout@cbs.knaw.nl

\footnotetext{
1 Centraalbureau voor Schimmelcultures, Uppsalalaan 8, 3584 CT Utrecht, The Netherlands

2 Rosenstiel School of Marine and Atmospheric Sciences, University of Miami, 4600 Rickenbacker Causeway, Key Biscayne, FL 33149, USA

3 Department of Epidemiology \& Biostatistics, Erasmus University Medical Centre, PO Box 1738, 3000

DR Rotterdam, The Netherlands

4 Institut Pasteur, Unité de Mycologie, Rue du Dr Roux, 75724 Paris Cedex 15, France

5 Molecular Mycology Laboratory, University of Sydney at Westmead Hospital, Westmead, NSW, Australia
}

\begin{abstract}
Amplified fragment length polymorphism (AFLP) genotyping of isolates of the pathogenic fungus Cryptococcus neoformans suggested a considerable genetic divergence between the varieties $C$. neoformans var. neoformans and $C$. neoformans var. grubii on the one hand versus $C$. neoformans var. gattii on the other. This divergence is supported by additional phenotypic, biochemical, clinical and molecular differences. Therefore, the authors propose the existence of two species, C. neoformans (Sanfelice) Vuillemin and C. bacillisporus Kwon-Chung, which differ in geographical distribution, serotypes and ecological origin. Within each species three AFLP genotypes occur, which differ in geographical distribution and serotypes. Differences in ecological origin (AIDS patients, non-AIDS patients, animals or the environment) were found to be statistically not significant. In C. neoformans as well as in C. bacillisporus one of the genotypes represented a hybrid. The occurrence of hybridization has consequences for the reproductive biology of the species, as new genotypes with altered virulence or susceptibility to antifungal drugs may arise through the exchange of genetic material.
\end{abstract}

Keywords: Cryptococcus neoformans, systematics, hybrids, geography, serotypes, AFLP

\section{INTRODUCTION}

Cryptococcus neoformans is a clinically important basidiomycetous yeast (Howard \& Kwon-Chung, 1995). The fungus belongs to the order Tremellales (jelly fungi) of the Hymenomycetes (Fell et al., 2000), a group of fungi commonly occurring on woody substrates. The species is known in both the asexual (anamorph) and sexual (teleomorph) state, for which the respective names Cryptococcus neoformans (Sanfelice) Vuillemin and Filobasidiella neoformans Kwon-Chung are used. In nature the fungus occurs, to our present knowledge, only in the asexual state. C. neoformans can cause lifethreatening infections in humans, especially in immunocompromised patients. Estimates of the incidence rate in

Abbreviations: AFLP, amplified fragment length polymorphism; CCV, cophenetic correlation value; CSF, cerebrospinal fluid; IGS, intergenic spacer; RAPD, random amplified polymorphic DNA; UPGMA, unweighted pair group method using arithmetic means.
AIDS patients range from 5 to $30 \%$, with the highest numbers occurring in sub-Saharan Africa (Mitchell \& Perfect, 1998), while other estimates set the upper limit at $6-12 \%$ (Casadevall \& Perfect, 1995). The main sites of infection are the lungs and the central nervous system, including cerebrospinal fluid (CSF), while most skin infections are probably due to disseminated systemic infections (Casadevall \& Perfect, 1998; Schupbach et al., 1976).

According to the current classification, the species consists of three varieties: C. neoformans var. neoformans (serotype D), C. neoformans var. grubii Franzot et al. (serotype A) (Franzot et al., 1999), both comprising the teleomorph F. neoformans var. neoformans KwonChung, and C. neoformans variety gattii Vanbreuseghem \& Takashio (serotypes B and C) with the teleomorph F. neoformans var. bacillispora KwonChung (Franzot et al., 1999; Kwon-Chung, 1975, 1976; Kwon-Chung \& Bennett, 1984; Kwon-Chung et al., 1978, 1982a, b; Pfeiffer \& Ellis, 1993). Variety grubii 
Table 1. Origins of isolates of C. neoformans and C. bacillisporus studied

\begin{tabular}{|c|c|c|c|c|}
\hline Strain & $\begin{array}{c}\text { AFLP } \\
\text { genotype }\end{array}$ & Serotype* & Origin $\dagger$ & Location \\
\hline \multicolumn{5}{|l|}{ C. neoformans } \\
\hline CBS 132 & 3 & $\mathrm{D}$ & Fermenting fruit juice, T Cryptococcus neoformans & Italy \\
\hline CBS 464 & 3 & $A^{*}$ & Unknown & France \\
\hline CBS 879 & 1 & A & Ulcerated cheek & Unknown \\
\hline CBS 882 & 2 & $\mathrm{D}$ & Nasal tumour of horse, $\mathrm{T}$ Torula nasalis & USA \\
\hline CBS 886 & 1 & A & Unknown & Unknown \\
\hline CBS 887 & 1 & A & Unknown & Unknown \\
\hline CBS 888 & 2 & $\mathrm{D}$ & Unknown & Unknown \\
\hline CBS 889 & 1 & $A^{*}$ & Unknown & Unknown \\
\hline CBS 916 & 1 & A & Unknown & Unknown \\
\hline CBS 918 & 2 & $\mathrm{D}$ & Dead white mouse & Netherlands \\
\hline CBS 939 & 3 & $D^{*}$ & Unknown & Unknown \\
\hline CBS 950 & 3 & $\mathrm{AD}^{*}$ & Tumour & Unknown \\
\hline CBS 996 & 1 & A & Blastomycosis from man, T Candida psicrophylicus & Argentina \\
\hline CBS 1144 & 1 & A & CSF & Unknown \\
\hline CBS 1931 & 1 & $\mathrm{~A}$ & Soil & Unknown \\
\hline CBS 1932 & $1 \mathrm{~A}$ & A & Soil & Unknown \\
\hline CBS 1935 & 1 & A & Soil & Unknown \\
\hline CBS 2771 & 1 & A & CSF & Unknown \\
\hline CBS 4194 & 2 & $\mathrm{D}$ & Spleen & Germany \\
\hline CBS 5467 & 2 & $\mathrm{D}$ & Milk from mastitic cow & Switzerland \\
\hline CBS 5474 & 2 & $\mathrm{D}$ & Mastitic cow & Unknown \\
\hline CBS 5728 & 2 & $\mathrm{D}$ & Non-meningitic cellulitis & USA \\
\hline CBS 5756 & 1 & $\mathrm{~A}$ & Unknown & Unknown \\
\hline CBS 6885 (NIH 12) & 2 & $\mathrm{D}$ & Lesion on bone in man, T Filobasidiella neoformans & USA \\
\hline CBS 6886 (NIH 430) & 2 & $\mathrm{D}$ & Pigeon droppings & Denmark \\
\hline $\begin{array}{l}\text { CBS } 6900(\mathrm{NIH} \\
\text { B-3501) }\end{array}$ & 2 & $\mathrm{D}$ & Genetic offspring of CBS $6885 \times 6886$ & \\
\hline $\begin{array}{l}\text { CBS } 6901(\mathrm{NIH} \\
\text { B-3502) }\end{array}$ & 2 & $\mathrm{D}$ & Genetic offspring of CBS $6885 \times 6886$ & \\
\hline CBS 6961 & 1 & $A^{*}$ & Man & USA \\
\hline CBS 6995 & 2 & $D^{*}$ & CSF non-AIDS patient & USA \\
\hline CBS 6999 & 1 & A & Pigeon droppings & Thailand \\
\hline CBS 7000 & 2 & $\mathrm{D}$ & Pigeon droppings & Denmark \\
\hline CBS 7779 & 1 & A & AIDS patient, urease-negative & Argentina \\
\hline CBS 7812 & 1 & A & CSF non-AIDS patient & Unknown \\
\hline CBS 7814 & 2 & $D^{*}$ & Air & Belgium \\
\hline CBS 7815 & 2 & $\mathrm{D}$ & Pigeon droppings & $\begin{array}{l}\text { Former } \\
\text { Czechoslovakia }\end{array}$ \\
\hline CBS 7816 & 2 & $D^{*}$ & Cuckoo droppings & Thailand \\
\hline CBS 7821 & 3 & $\mathrm{AD}$ & Single basidiospore $6886 \times 7814$ (ATCC 42161 ) & \\
\hline CBS 7822 & 2 & $D^{*}$ & Single basidiospore $6885 \times 6886$ & \\
\hline CBS 7824 & ? & $D^{*}$ & Single basidiospore 7816 & \\
\hline CBS 7825 & ? & $\mathrm{AD}$ & Single basidiospore 7816 & \\
\hline CBS 8336 & 1 & A & Decaying wood of Cassia tree & Brazil \\
\hline CBS 8337 & 1 & A & Decaying wood of Cassia tree & Brazil \\
\hline CBS 8710 & 1 & A & $\begin{array}{l}\text { Hodgkin's disease, T Cryptococcus neoformans var. } \\
\text { grubii }\end{array}$ & USA \\
\hline Hamdan 214-L & $1 \mathrm{~A}$ & A & AIDS patient & Brazil \\
\hline Hamdan 299 & $1 \mathrm{~A}$ & A & AIDS patient & Brazil \\
\hline Hamdan $822 b$ & 1 & A & AIDS patient & Brazil \\
\hline Hamdan C3-1 & $1 \mathrm{~A}$ & A & Pigeon droppings & Brazil \\
\hline Hamdan C31 & $1 \mathrm{~A}$ & $\mathrm{~A}$ & AIDS patient & Brazil \\
\hline Hamdan F2'1 & 1 & A & Pigeon droppings & Brazil \\
\hline Hamdan I3'1 & 1 & A & Pigeon droppings & Brazil \\
\hline
\end{tabular}


Table 1 (cont.)

\begin{tabular}{|c|c|c|c|c|}
\hline Strain & $\begin{array}{c}\text { AFLP } \\
\text { genotype }\end{array}$ & Serotype* & Origin $†$ & Location \\
\hline Hamdan MCP-2 & $1 \mathrm{~A}$ & A & Pigeon droppings & Brazil \\
\hline Hamdan WP & 1 & A & AIDS patient & Brazil \\
\hline J10 & 1 & A & AIDS patient & USA \\
\hline J11 & $1 \mathrm{~A}$ & A & AIDS patient & USA \\
\hline J15 & 1 & $\mathrm{~A}$ & AIDS patient & USA \\
\hline $\mathrm{J} 22 \mathrm{a}$ & 3 & $\mathrm{D}$ & AIDS patient & USA \\
\hline $\mathrm{J} 40$ & 3 & $\mathrm{D}$ & AIDS patient & USA \\
\hline J51 & 1 & A & AIDS patient & USA \\
\hline J9 & 2 & $D^{*}$ & AIDS patient & USA \\
\hline NIH 192 & 1 & A & Desert soil & USA \\
\hline NIH 193 & 1 & A & Soil & USA \\
\hline NIH 296 & 1 & A & Non-AIDS patient & USA \\
\hline NIH 311 & 1 & A & Non-AIDS patient & USA \\
\hline NIH 443 & 1 & A & Soil & USA \\
\hline NIH 449 & 1 & A & Non-AIDS patient & USA \\
\hline P050 & 1 & A & AIDS patient & Zimbabwe \\
\hline P056 & 1 & A & AIDS patient & Zimbabwe \\
\hline P090 & 1 & A & AIDS patient & Zimbabwe \\
\hline P139 & 1 & A & AIDS patient & Zimbabwe \\
\hline P140 & 1 & A & AIDS patient & Zimbabwe \\
\hline P141 & 1 & A & AIDS patient & Zimbabwe \\
\hline P152 & 1 & A & AIDS patient & Zimbabwe \\
\hline P172 & 1 & A & AIDS patient & Zimbabwe \\
\hline RV26952 & 1 & A & CSF, non-AIDS patient & Zaire \\
\hline RV46115 & 1 & A & Plants & India \\
\hline RV46119 & 1 & $\mathrm{~A}$ & Pigeon droppings & India \\
\hline RV46129 & 1 & A & Pigeon droppings & India \\
\hline RV52733 & 3 & $\mathrm{D}$ & Pigeon droppings & Belgium \\
\hline RV52755 & 3 & $D^{*}$ & CSF, non-AIDS patient & Belgium \\
\hline RV53794 & 3 & $\mathrm{D}$ & Canary droppings & Belgium \\
\hline RV55446 & 1 & $\mathrm{~A}$ & House dust & Zaire \\
\hline RV55451 & 1 & A & Cockroach & Zaire \\
\hline RV55980 & 1 & A & Canary droppings & Belgium \\
\hline RV56126 & $1 \mathrm{~A}$ & A & CSF, AIDS patient & Belgium (visited Haiti) \\
\hline RV56883 & 1 & A & Canary droppings & Belgium \\
\hline RV56894 & 1 & A & Canary droppings & Belgium \\
\hline RV58145 & 1 & A & Wood & Zaire \\
\hline RV58146 & $1 \mathrm{~A}$ & A & Wood & Zaire \\
\hline RV59351 & 1 & A & Parrot droppings & Belgium \\
\hline RV59369 & 1 & A & Parrot droppings & Belgium \\
\hline RV59379 & 1 & A & Air in zoo & Belgium \\
\hline RV60074 & 1 & $A *$ & Skin cryptococcosis, non-AIDS patient & Belgium \\
\hline RV61756 & $1 \mathrm{~A}$ & $\mathrm{AD}$ & Man & Belgium (visited Zaire) \\
\hline RV61790 & 1 & A & Man & Belgium \\
\hline RV62210 & 1 & A & CSF, AIDS patient & Belgium \\
\hline RV62692 & 2 & $\mathrm{D}$ & Skin cryptococcosis & Belgium \\
\hline RV63214 & 1 & A & CSF, AIDS patient & Zaire \\
\hline RV63642 & 1 & A & CSF, AIDS patient & Brazil \\
\hline RV64610 & $1 \mathrm{~A}$ & A & AIDS patient & Rwanda \\
\hline RV64612 & 1 & A & AIDS patient & Rwanda \\
\hline RV65361 & 1 & A & CSF, probably AIDS patient & Zaire \\
\hline RV65662 & $1 \mathrm{~A}$ & A & AIDS patient & Portugal \\
\hline RV66025 & 1 & A & Cryptococcoma, non-AIDS patient & Belgium \\
\hline RV66055 & 1 & A & AIDS patient & Rwanda \\
\hline WM164 & $1 \mathrm{~A}$ & A & Pigeon droppings & Australia \\
\hline
\end{tabular}


Table 1 (cont.)

\begin{tabular}{|c|c|c|c|c|}
\hline Strain & $\begin{array}{l}\text { AFLP } \\
\text { genotype }\end{array}$ & Serotype* & Origin $†$ & Location \\
\hline WM361 & 1 & $\mathrm{~A}$ & CSF AIDS patient & Thailand \\
\hline WM364 & 1 & $\mathrm{~A}$ & CSF AIDS patient & Thailand \\
\hline WM374 & 1 & A & CSF AIDS patient & Thailand \\
\hline WM375 & 1 & A & CSF AIDS patient & Thailand \\
\hline WM553 & $1 \mathrm{~A}$ & A & House dust & Brazil \\
\hline WM554 & 1 & $\mathrm{~A}$ & Dust from pigeon & Brazil \\
\hline WM555 & 1 & $\mathrm{~A}$ & Dust from pigeon & Brazil \\
\hline WM712 & 1 & $\mathrm{~A}$ & Cat paranasal & Australia \\
\hline WM713 & 1 & $\mathrm{~A}$ & Cat paranasal & Australia \\
\hline WM714 & 1 & $\mathrm{~A}$ & Cat paranasal & Australia \\
\hline WM715 & 1 & $\mathrm{~A}$ & Pine needles & Australia \\
\hline WM716 & 1 & $\mathrm{~A}$ & Woody debris of Eucalyptus camaldulensis & Australia \\
\hline WM719 & 1 & $\mathrm{~A}$ & AIDS patient & South Africa \\
\hline WM720 & 1 & A & Pigeon droppings & India \\
\hline WM721 & 1 & A & Pigeon droppings & India \\
\hline WM722 & 1 & A & Pigeon droppings & India \\
\hline WM723 & 1 & $\mathrm{~A}$ & Environmental isolate & USA \\
\hline WM724 & 1 & $\mathrm{~A}$ & Debris of Eucalyptus & USA \\
\hline WM725 & 1 & A & Debris, zoo hippo cage & USA \\
\hline 110B & 1 & $\mathrm{~A}$ & Environmental isolate & France \\
\hline $122 \mathrm{~A}$ & 1 & $\mathrm{~A}$ & Environmental isolate & France \\
\hline $12 \mathrm{~A}$ & 1 & $\mathrm{~A}$ & Environmental isolate & France \\
\hline $13 \mathrm{~A}$ & 1 & $\mathrm{~A}$ & Environmental isolate & France \\
\hline $20 \mathrm{~B}$ & 2 & $\mathrm{D}$ & Environmental isolate & France \\
\hline $22 \mathrm{~A}$ & 2 & $\mathrm{D}$ & Environmental isolate & France \\
\hline $385 \mathrm{D}$ & 2 & $\mathrm{D}$ & Unknown & USA? \\
\hline $57 \mathrm{~B}$ & 1 & $\mathrm{~A}$ & Environmental isolate & France \\
\hline RDA 1335 AvB0 & 1 & $\mathrm{~A}$ & AIDS patient no. 1 & Netherlands \\
\hline RDA 1340 AvB1 & 1 & $\mathrm{~A}$ & AIDS patient no. 1 & Netherlands \\
\hline RDA 4092 AvB10 & 1 & $\mathrm{~A}$ & AIDS patient no. 9 & Netherlands \\
\hline RDA 4094 AvB11 & 1 & A & AIDS patient no. 10 & Netherlands \\
\hline RDA 4054 AvB12 & 1 & $\mathrm{~A}$ & AIDS patient no. 11 & Netherlands \\
\hline RDA 4091 AvB13 & 1 & $\mathrm{~A}$ & AIDS patient no. 12 & Netherlands \\
\hline RDA 1371 AvB2 & 1 & $\mathrm{~A}$ & AIDS patient no. 2 & Netherlands \\
\hline RDA 1369 AvB3 & 1 & $\mathrm{~A}$ & AIDS patient no. 3 & Netherlands \\
\hline RDA 1373 AvB4 & 1 & $\mathrm{~A}$ & AIDS patient no. 3 & Netherlands \\
\hline RDA 1549 AvB7 & 1 & $\mathrm{~A}$ & AIDS patient no. 6 & Netherlands \\
\hline B10 & 1 & $\mathrm{~A}$ & Environmental isolate & USA \\
\hline B3 & 1 & $\mathrm{~A}$ & Environmental isolate & USA \\
\hline B5 & 1 & $\mathrm{~A}$ & Environmental isolate & USA \\
\hline BA1 & 3 & $D^{*}$ & AIDS patient & France \\
\hline BA3 & 3 & $\mathrm{AD}^{*}$ & AIDS patient & France \\
\hline BA4 & 3 & $\mathrm{AD}^{*}$ & AIDS patient & France \\
\hline BA5 & 3 & $\mathrm{AD}^{*}$ & AIDS patient & France \\
\hline BD1 & 2 & $\mathrm{D}$ & AIDS patient & France \\
\hline BD2 & 1 & A & AIDS patient & France \\
\hline BD3 & 2 & $\mathrm{D}$ & AIDS patient & France \\
\hline BD5 & 2 & $\mathrm{D}$ & AIDS patient & France \\
\hline \multicolumn{5}{|l|}{ C. bacillisporus } \\
\hline CBS 883 & $4 \mathrm{~B}$ & $\mathrm{~B}$ & Infected skin, syntype C. hondurianus & Honduras \\
\hline CBS 919 & $4 \mathrm{~A}$ & $\mathrm{~B}$ & $\begin{array}{l}\text { Meningoencephalic lesion, T Torulopsis neoformans } \\
\text { var. sheppei }\end{array}$ & USA \\
\hline CBS 1622 & $4 \mathrm{~A}$ & $\mathrm{~B}$ & Tumour & Unknown \\
\hline CBS 1930 & 6 & $\mathrm{~B}$ & Sick goat & Aruba \\
\hline
\end{tabular}


Table 1 (cont.)

\begin{tabular}{|c|c|c|c|c|}
\hline Strain & $\begin{array}{l}\text { AFLP } \\
\text { genotype }\end{array}$ & Serotype* & Origin $\dagger$ & Location \\
\hline CBS 1934 & $4 \mathrm{~A}$ & $\mathrm{~B}$ & Mastitic cow & USA \\
\hline CBS 5757 & $4 \mathrm{~A}$ & $\mathrm{~B}$ & Unknown & Unknown \\
\hline CBS 5758 & $5 \mathrm{C}$ & $\mathrm{C}$ & Unknown & Unknown \\
\hline CBS 6289 & $4 \mathrm{~A}$ & $\mathrm{~B}$ & $\begin{array}{l}\text { Subculture of type strain of C. neoformans var. } \\
\text { gattii (RV20186) }\end{array}$ & Zaire \\
\hline CBS 6290 & $4 \mathrm{~A}$ & $\mathrm{~B}$ & Man & Zaire \\
\hline CBS 6955 (NIH 191) & $5 \mathrm{C}$ & $\mathrm{C}$ & CSF, T Filobasidiella bacillispora & USA \\
\hline CBS 6956 (NIH 444) & 6 & $\mathrm{~B}$ & Sputum & USA \\
\hline CBS 6992 (NIH 17) & $4 \mathrm{~A}$ & $\mathrm{~B}$ & Man & USA \\
\hline CBS 6993 (NIH 18) & $5 \mathrm{C}$ & $\mathrm{C}$ & Man & USA \\
\hline CBS 6994 (NIH 34) & $5 \mathrm{C}$ & $\mathrm{C}$ & CSF & USA \\
\hline CBS 6997 (NIH 298) & $5 \mathrm{C}$ & $\mathrm{B}$ & CSF & USA \\
\hline CBS 7229 & 4B & $\mathrm{B}$ & Meningitis, T C. neoformans var. shanghaiensis & China \\
\hline CBS 7523 & $4 \mathrm{~B}$ & $\mathrm{~B}$ & Eucalyptus camaldulensis & Australia \\
\hline CBS 7740 & $4 \mathrm{~B}$ & $\mathrm{~B}$ & CSF & India \\
\hline CBS 7742 & $4 \mathrm{~B}$ & $\mathrm{~B}$ & CSF & India \\
\hline CBS 7747 & $4 \mathrm{~B}$ & $\mathrm{~B}$ & Olive seedling & Australia \\
\hline CBS 7748 & $4 \mathrm{~B}$ & $\mathrm{~B}$ & Air in hollow Eucalyptus camaldulensis & Australia \\
\hline CBS 7749 & $4 \mathrm{~B}$ & $\mathrm{~B}$ & Bark debris of Eucalyptus camaldulensis & Australia \\
\hline CBS 7750 & 6 & $\mathrm{~B}$ & Bark debris of Eucalyptus camaldulensis & USA \\
\hline CBS 8684 & 6 & $\mathrm{~B}$ & Nest of wasp & Uruguay \\
\hline $\begin{array}{l}\text { CBS } 8755 \text { (HOO58- } \\
\text { I-682) }\end{array}$ & $5 \mathrm{~A}$ & $\mathrm{C}$ & Detritus of almond tree & Colombia \\
\hline $\begin{array}{l}\text { CBS } 8756 \text { (HOO58- } \\
\text { I-818) }\end{array}$ & $5 \mathrm{~A}$ & $\mathrm{C}$ & Detritus of almond tree & Colombia \\
\hline CDC B-5751 & $4 \mathrm{~B}$ & $\mathrm{~B}$ & CSF, non-AIDS patient & India \\
\hline CDC 5765 & $4 \mathrm{~B}$ & $\mathrm{~B}$ & Flowers of Eucalyptus camaldulensis & India \\
\hline NIH 139 & $5 \mathrm{C}$ & $\mathrm{C}$ & Non-AIDS patient & USA \\
\hline NIH 178 & $5 \mathrm{C}$ & $\mathrm{C}$ & Non-AIDS patient & USA \\
\hline NIH 189 & $5 \mathrm{~B}$ & $\mathrm{~B}$ & Non-AIDS patient & USA \\
\hline NIH 190 & $5 \mathrm{~B}$ & $\mathrm{~B}$ & Non-AIDS patient & USA \\
\hline RV20186 & $4 \mathrm{~A}$ & $\mathrm{~B}$ & CSF & Zaire \\
\hline RV5265 & $4 \mathrm{~A}$ & $\mathrm{~B}$ & CSF & Zaire \\
\hline RV54130 & $4 \mathrm{~B}$ & $\mathrm{~B}$ & Second isolate of C. neoformans var. shanghaiensis & China \\
\hline RV66095 & $4 \mathrm{~A}$ & $\mathrm{~B}$ & CSF non-AIDS patient & Brazil \\
\hline WM161 & $5 \mathrm{~B}$ & $\mathrm{~B}$ & Debris of Eucalyptus spp. & USA \\
\hline WM176 & $4 \mathrm{~B}$ & $\mathrm{~B}$ & Eucalyptus citriodora & USA \\
\hline WM717 & $4 \mathrm{~B}$ & $\mathrm{~B}$ & Woody debris of Eucalyptus tericornis & USA \\
\hline WM718 & $4 \mathrm{~B}$ & $\mathrm{~B}$ & Woody debris of Eucalyptus tericornis & USA \\
\hline WM726 & $5 \mathrm{~B}$ & $\mathrm{~B}$ & Eucalyptus citriodora & USA \\
\hline WM727 & $4 \mathrm{~A}$ & $\mathrm{~B}$ & Debris of Eucalyptus from car park of zoo & USA \\
\hline WM728 & $5 \mathrm{~B}$ & $\mathrm{~B}$ & Debris of Eucalyptus from car park of zoo & USA \\
\hline $380 \mathrm{C}$ & $5 \mathrm{C}$ & $\mathrm{C}$ & Unknown & Unknown \\
\hline $381 \mathrm{C}$ & $5 \mathrm{C}$ & $\mathrm{C}$ & Unknown & USA \\
\hline $384 \mathrm{C}$ & $5 \mathrm{C}$ & $\mathrm{C}$ & Patient & USA \\
\hline $385 \mathrm{C}(=\mathrm{NIH} 18)$ & $5 \mathrm{~B}$ & $\mathrm{C}$ & Unknown & USA \\
\hline $48 \mathrm{~A}$ & $4 \mathrm{~A}$ & B & Lung of a goat & Spain \\
\hline $52 \mathrm{~A}$ & $4 \mathrm{~A}$ & $\mathrm{~B}$ & Brain of a goat & Spain \\
\hline $55 \mathrm{~A}$ & $4 \mathrm{~A}$ & $\mathrm{~B}$ & Lung of a goat & Spain \\
\hline $56 \mathrm{~A}$ & $4 \mathrm{~A}$ & $\mathrm{~B}$ & Gut of a goat & Spain \\
\hline $59 \mathrm{~A}$ & $4 \mathrm{~A}$ & $\mathrm{~B}$ & Lung of a goat & Spain \\
\hline $60 \mathrm{~A}$ & $4 \mathrm{~A}$ & $\mathrm{~B}$ & Lung of a goat & Spain \\
\hline
\end{tabular}

"In the case of anomalous results, serotypes were redetermined using immunofluorescence with monoclonal antibody (Dromer et al., 1993) and agglutination with the IatronO kit (Ikeda et al., 1982). These are indicated with an asterisk.

† T, type strain. 


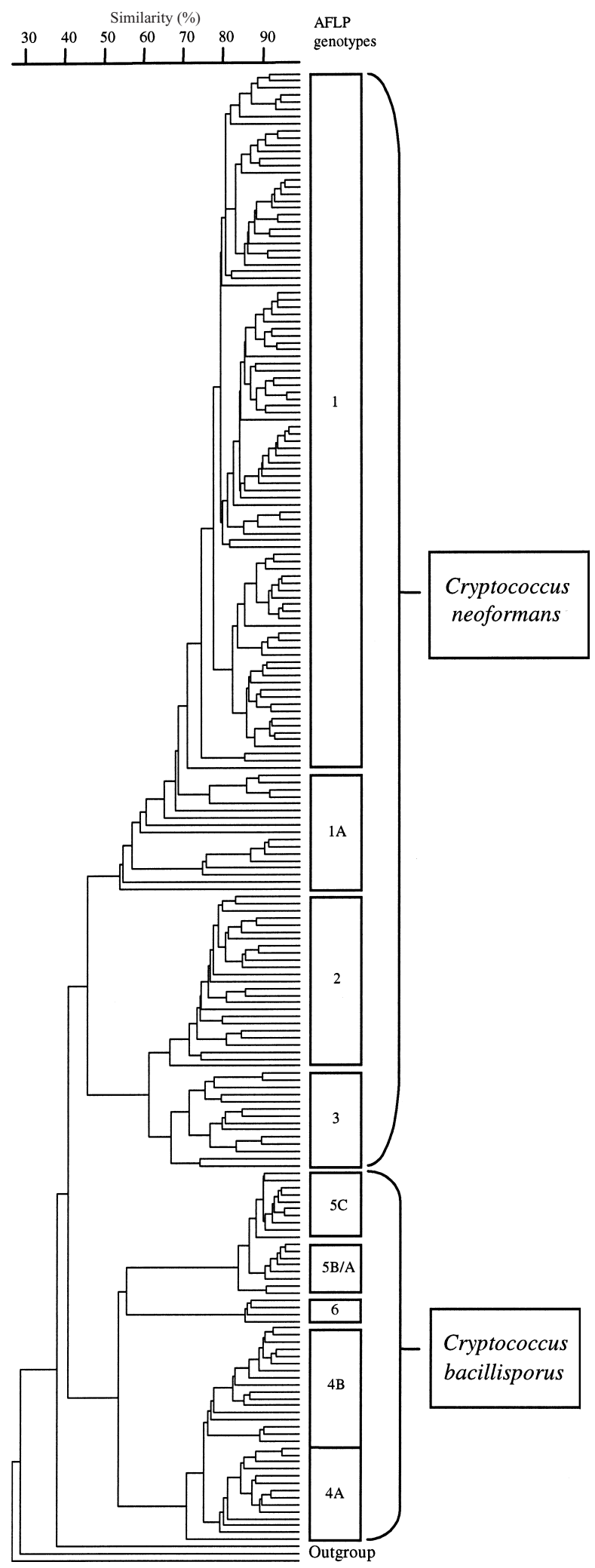

Fig. 1. Clustering of AFLP banding patterns of isolates of $C$. neoformans and $C$. bacillisporus ( $=C$. neoformans var. gattii) by UPGMA. Two main branches, each with three genotypes, can be distinguished. Genotypes 3 and 6 represent hybrid genotypes. was recently recognized for serotype $A$ isolates based on molecular data such as DNA fingerprints and URA5 sequences (Franzot et al., 1999). This variety is encountered in nearly all of the AIDS-related infections in the USA (Casadevall \& Perfect, 1998; Kovacs et al., 1985).

The varieties neoformans and grubii differ from variety gattii in their electrophoretic karyotypes (Boekhout et al., 1997; Wickes et al., 1994), random amplified polymorphic DNA (RAPD) (Boekhout et al., 1997), DNA fingerprints (Varma et al., 1995), PCR fingerprints (Meyer \& Mitchell, 1995; Meyer et al., 1993), intergenic spacer (IGS) sequences of the rDNA (Diaz et al., 2001), a number of physiological and biochemical characteristics (Bennett et al., 1978; Cherniak \& Sundstrom, 1994; Dufait et al., 1987; Kwon-Chung et al., 1987; Mukaramangwa et al., 1995; Polacheck \& KwonChung, 1980), susceptibility to killer toxins of C. laurentii CBS 139 (Boekhout \& Scorzetti, 1997), geographical distribution and habitat (Casadevall \& Perfect, 1998; Kwon-Chung \& Bennett, 1984), and clinical manifestation (Kwon-Chung et al., 1988; Speed \& Dunt, 1995). Current views based on different genetic typing methods, such as RAPD, DNA and PCR fingerprints, and URA5 sequences, suggest that serotypes $\mathrm{A}$ and $\mathrm{D}$ form distinct genetic lineages (Boekhout et al., 1997; Franzot et al., 1998a, 1999; Meyer \& Mitchell, 1995; Varma et al., 1995).

In this study we used amplified fragment length polymorphism (AFLP) (Blears et al., 1998; Janssen et al., 1996; Savelkoul et al., 1999; Zabeau \& Vos, 1993) to investigate the genetic structure and epidemiological relationships of a range of cryptococcal isolates collected worldwide.

\section{METHODS}

Strains, media and serotyping. The strains studied listed in Table 1 (see also http://www.cbs.knaw.nl/publications/ online/hybrids_cryptococcus_neoformans), were maintained on YPGA ( $1 \%$ yeast extract, $0.5 \%$ peptone, $4 \%$ glucose agar) at $10{ }^{\circ} \mathrm{C}$ and stored at $-80^{\circ} \mathrm{C}$. One hundred and fifty-three isolates of C. neoformans var. neoformans and 54 of C. neoformans var. gattii were studied from AIDS and non-AIDS patients, the environment and animals, and from all continents (except Antarctica). Isolates were obtained from CBS (Utrecht, The Netherlands), the Prince Leopold Institute for Tropical Medicine (Antwerp, Belgium), the National Institutes of Health (Bethesda, MD, USA), the University of Sydney at Westmead Hospital (Sydney, Australia), and from individual researchers from Colombia, Spain, USA, Brazil and France. Data on the serotypes were taken from the literature (Boekhout et al., 1997) or provided by the depositors of the isolates. In the case of anomalous results, serotypes were redetermined using immunofluorescence with monoclonal antibody (Dromer et al., 1993) and agglutination with the IatronO kit (Ikeda et al., 1982). These are indicated with an asterisk in Table 1. Filobasidiella depauperata (Petch) Samson et al. CBS 7844, Cryptococcus podzolicus (Bab'eva \& Reshetova) Golubev CBS 6819 and Mrakia frigida (Fell et al.) Yamada \& Komagata CBS 5917 were used as outgroups. 
Table 2. Percentages of isolates in the different serotype (a), clinical/environmental origin (b) and geographical origin (c) classes within the six AFLP genotypes of C. neoformans and C. bacillisporus

Figures are rounded off; figures in parentheses indicate the percentage of the total number of isolates.

\begin{tabular}{|c|c|c|c|c|c|c|c|c|}
\hline (a) & Genotype & A & D & $\mathrm{AD}$ & B & $\mathrm{C}$ & & \\
\hline & $1(n=112)$ & $99(55)$ & - & $1(0 \cdot 5)$ & - & - & & \\
\hline & $2(n=22)$ & - & $100(11)$ & - & - & - & & \\
\hline & $3(n=14)$ & $7(0 \cdot 5)$ & $57(4)$ & $36(2.5)$ & - & - & & \\
\hline & $4(n=30)$ & - & - & - & $100(15)$ & - & & \\
\hline & $5(n=18)$ & - & - & - & $33(3)$ & $67(6)$ & & \\
\hline & $6(n=4)$ & - & - & - & $100(2)$ & - & & \\
\hline (b) & Genotype & AIDS & Non-AIDS & Animal & Environmental & $?$ & & \\
\hline & $1(n=112)$ & $39(22)$ & $13(7 \cdot 5)$ & $5(2)$ & $39(22)$ & $4(2 \cdot 5)$ & & \\
\hline & $2(n=22)$ & $17(2)$ & $21(2 \cdot 5)$ & $17(2)$ & $29(3 \cdot 5)$ & $16(1 \cdot 5)$ & & \\
\hline & $3(n=14)$ & $46(3)$ & $15(1)$ & - & $23(15)$ & $15(1)$ & & \\
\hline & $4(n=30)$ & - & $45(7)$ & $23(3 \cdot 5)$ & $29(4 \cdot 5)$ & $3(0 \cdot 5)$ & & \\
\hline & $5(n=18)$ & - & $50(4 \cdot 5)$ & - & $28(2 \cdot 5)$ & $22(2)$ & & \\
\hline & $6(n=4)$ & - & $25(0 \cdot 5)$ & $25(0 \cdot 5)$ & $50(1)$ & - & & \\
\hline (c) & Genotype & NAm. & SAm. & Eur. & Afr. & Asia & Austr. & $?$ \\
\hline & $1(n=112)$ & $16(9)$ & $15(8 \cdot 5)$ & $26(14 \cdot 5)$ & $17(8 \cdot 5)$ & $10(5 \cdot 5)$ & $5(3)$ & $11(6)$ \\
\hline & $2(n=22)$ & $26(3)$ & - & $57(6 \cdot 5)$ & - & $4(0 \cdot 5)$ & - & $13(1 \cdot 5)$ \\
\hline & $3(n=14)$ & 15 (1) & - & $69(4 \cdot 5)$ & - & - & - & $15(1)$ \\
\hline & $4(n=30)$ & $19(3)$ & $7(1)$ & $19(3)$ & $13(2)$ & $19(3)$ & $16(2 \cdot 5)$ & $7(1)$ \\
\hline & $5(n=18)$ & $78(7)$ & $16(1)$ & - & - & - & - & $16(1)$ \\
\hline & $6(n=4)$ & $50(1)$ & $50(1)$ & - & - & - & - & - \\
\hline
\end{tabular}

DNA isolation and AFLP. For DNA isolation, cells were harvested from 2-3-d-old cultures and lyophilized. DNA was isolated by the CTAB method (O’Donnell et al., 1997). The AFLP procedure was performed according to the 'AFLP Microbial Fingerprinting Protocol' of the manufacturer (PE Biosystems), with some modifications. Restriction-ligation was performed simultaneously on $10 \mathrm{ng}$ genomic DNA, using 1 unit MseI, 5 units EcoRI and 3 units T4 DNA Ligase (Biolabs). The reaction took place in a total volume of $5.5 \mu \mathrm{l}$ with $0.36 \mu \mathrm{M}$ EcoRI adaptor and $3.64 \mu \mathrm{M}$ MseI adaptor from the AFLP Microbial Fingerprinting Kit (PE Biosystems), $0 \cdot 1 \mathrm{M}$ $\mathrm{NaCl}, 0.91 \mathrm{mM}$ Tris/ $\mathrm{HCl}$ (pH 7.8), 0.18 mM MgCl, $0.18 \mathrm{mM}$ dithiothreitol, $18 \mu \mathrm{M}$ ATP and $91.36 \mu \mathrm{g} \mathrm{BSA} \mathrm{ml}{ }^{-1}$. The restriction-ligation mixture was incubated for $2 \mathrm{~h}$ at $37^{\circ} \mathrm{C}$ and diluted by adding $25 \mu \mathrm{l}$ sterile bidistilled water. The first PCR was performed with the two preselective primers (EcoRI core sequence and MseI core sequence) and 'AFLP Amplification Core Mix' from the 'AFLP Microbial Fingerprinting Kit' according to the manual, under the following conditions: $2 \mathrm{~min}$ at $72{ }^{\circ} \mathrm{C}$, followed by 20 cycles of $20 \mathrm{~s}$ at $94{ }^{\circ} \mathrm{C}, 30 \mathrm{~s}$ at $56^{\circ} \mathrm{C}$ and $2 \mathrm{~min}$ at $72{ }^{\circ} \mathrm{C}$. The PCR product was diluted by adding $25 \mu \mathrm{l}$ sterile bidistilled water. A second PCR used more selective primers: EcoRI-AC FAM and MseI-G. The conditions were: $2 \mathrm{~min}$ at $94^{\circ} \mathrm{C}$, followed by 10 cycles consisting of $20 \mathrm{~s}$ at $94^{\circ} \mathrm{C}, 30 \mathrm{~s}$ at $66^{\circ} \mathrm{C}$ decreasing $1{ }^{\circ} \mathrm{C}$ every step of the cycle, and $2 \mathrm{~min}$ at $72^{\circ} \mathrm{C}$, followed by 25 cycles consisting of $20 \mathrm{~s}$ at $94^{\circ} \mathrm{C}, 30 \mathrm{~s}$ at $56^{\circ} \mathrm{C}$ and $2 \mathrm{~min}$ at $72^{\circ} \mathrm{C}$. The samples were prepared for acrylamide electrophoresis with the following loading mix: $1.0 \mu \mathrm{l}$ selective amplification product, $1 \cdot 25 \mu \mathrm{l}$ deionized formamide, $0 \cdot 25 \mu \mathrm{l}$ blue dextran in $50 \mathrm{mM}$ EDTA and $0.5 \mu \mathrm{l}$ GeneScan-500 [ROX] size standard. After incubation for $3 \mathrm{~min}$ at $95^{\circ} \mathrm{C}, 1.5 \mu \mathrm{lmix}$ was loaded and run for $3 \mathrm{~h}$ on a $5 \%$ polyacrylamide gel on the ABI 377 sequencer (PE Biosystems) using $1 \times \mathrm{TBE}$ running buffer. Data were analysed with the Bionumerics software package (version 1.01, Applied Maths, Kortrijk, Belgium), using (a) Pearson correlation based on similarities of the densitometric curves, and (b) the unweighted pair group method using arithmetic means (UPGMA) analysis with the Dice coefficient and the fuzzy logic option. Statistical significance of the clusters was tested by cophenetic correlation and bootstrap analysis. Statistical analysis of the resulting genotypes used chi-squared analysis by calculating exact $P$-values (SPSS 9.0 for Windows, SPSS Inc.).

\section{RESULTS}

\section{AFLP genotyping}

The AFLP genotyping resulted in a clear separation between $C$. neoformans var. neoformans and C. neoformans var. grubii (serotypes A, D and AD) versus 


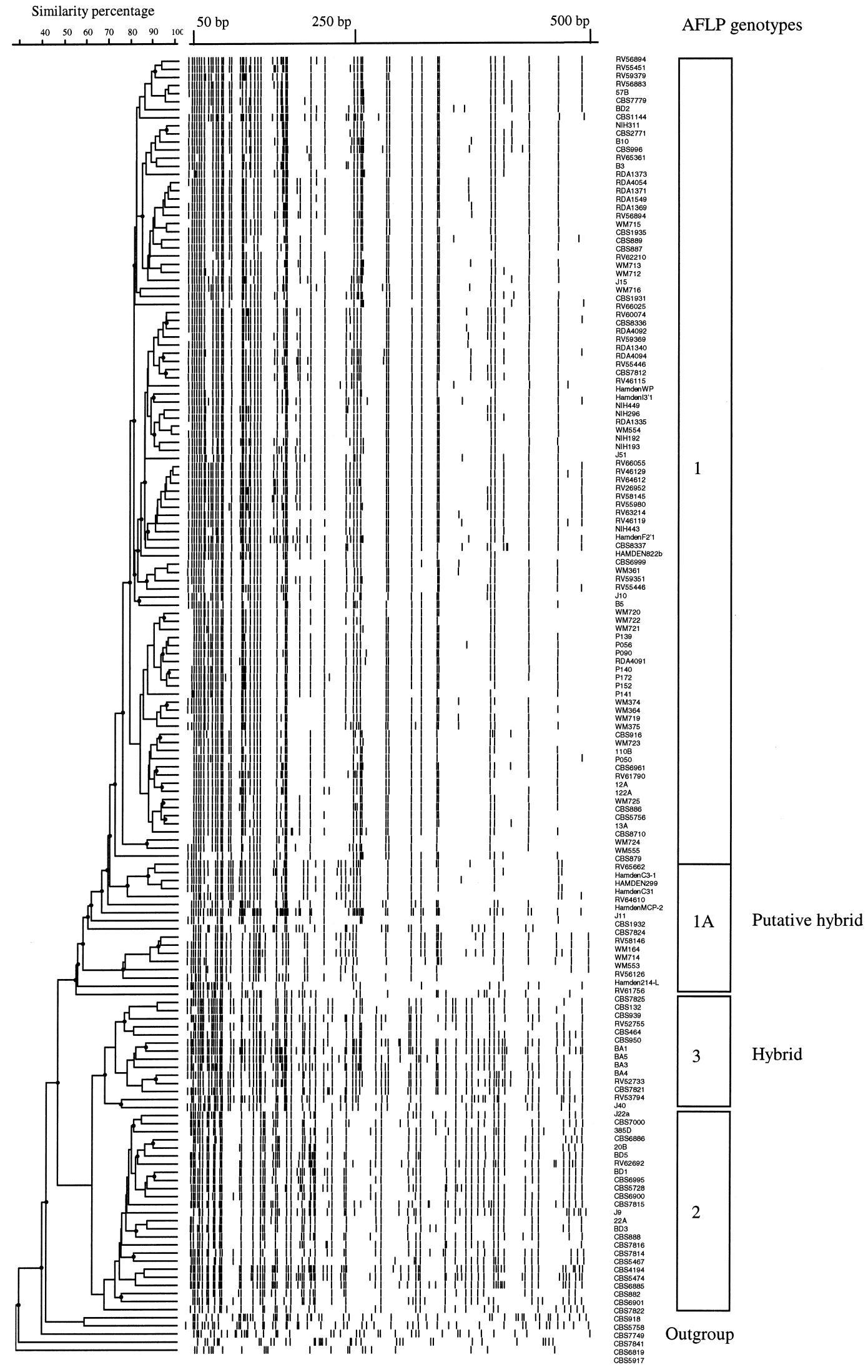

Fig. 2. Clustering of AFLP banding patterns of isolates of $C$. neoformans by UPGMA. Dots indicate well-supported clusters $(C C V \geqslant 85 \%)$. Note the hybrid pattern of genotype 3, containing bands occurring in both genotypes 1 and 2 . 
C. neoformans var. gattii (serotypes B and C), thus supporting the genetic separation between C. neoformans $/ F$. neoformans var. neoformans and C. neoformans var. gattii $(=C$. bacillisporus $) / F$. neoformans var. bacillispora (Fig. 1, Table 2). Almost all isolates possessed unique AFLP banding patterns. Six major genotypic clusters were found to be supported by high cophenetic correlation values (CCV). Three clusters (numbered 1-3) represented C. neoformans var. neoformans and C. neoformans var. grubii, and three clusters (numbered 4-6) C. neoformans var. gattii (Figs 1, 2 and 3). Both the terminal and deeper branches were strongly supported, but the intermediate branches usually lacked strong support (Figs 2 and 3). The majority $(56 \%)$ of the isolates belonged to cluster 1 ; $11.5 \%$ belonged to cluster $2,7 \cdot 0 \%$ to cluster $3 ; 15 \%$ to cluster $4 ; 9 \%$ to cluster 5 and $2 \%$ to cluster 6 . All isolates from AIDS patients were found in clusters 1-3. In the rest of this paper we have, for convenience, used the name C. neoformans for C. neoformans var. neoformans and C. neoformans var. grubii, and C. bacillisporus for C. neoformans var. gattii. The arguments for this species separation are given in the Discussion.

For both C. neoformans and C. bacillisporus the genotypes did not significantly differ in their ecological origin (viz. AIDS patients, non-AIDS patients, animals and environmental sources), with respective overall $P$ values of $0 \cdot 186$ and $0 \cdot 162$. However, within C. neoformans the geographical and serotype results were found to be highly significantly associated with the genotypes, with respective $P$-values of 0.002 and $<0.001$. Regarding geography and serotype distributions, the African population of C. neoformans was significantly different from the North American and European populations, with the Asian, Australian and South American populations intermediate (Fig. 4a). For C. bacillisporus the geographical and serotype outcomes were significantly associated with the genotypes, with overall $P$-values of 0.001 and $<0.001$, respectively. The North American population of C. bacillisporus is distinct from the African, Australian, European and Asian populations, with the South American population intermediate (Fig. 4b). We did not find a significant association between geographical origin and serotypes in C. bacillisporus $(P=0.095)$; this is in contrast to C. neoformans, where this association was significant $(P \leqslant 0 \cdot 001)$.

\section{C. neoformans}

Cluster 1 (= genotype 1 ) agreed with variety grubii, as all isolates were of serotype A (Table 2). Identical numbers of isolates were from environmental sources and AIDS patients (both 39\%), whereas lower numbers came from non-AIDS patients $(13 \%)$, animals $(5 \%)$ or from unknown origins $(4 \%)$. Members of this cluster were found to be present worldwide without an apparent geographical substructure (Table 2). No genetic differences were observed between the isolates from AIDS patients, non-AIDS patients, animals and the environment. The statistically supported subclusters contained isolates from different origins and localities. The isolates of genotype $1 \mathrm{~A}$ (Table 1), representing isolates of AIDS patients from Brazil, Rwanda, USA and Belgium, and from the environment in Brazil, Zaire and Australia, seem genetically different from isolates of genotype 1 because of the presence of additional bands (Fig. 2).

Cluster 2 (= genotype 2) contained only serotype D isolates (Table 2). Within our collection of isolates this cluster was represented in Europe $(57 \%)$, North America $(26 \%)$, Asia $(4 \%)$ and of unknown origin $(13 \%)$. The majority of isolates came from environmental sources $(29 \%)$ and non-AIDS patients $(21 \%)$, and fewer from AIDS patients $(17 \%)$, animals $(17 \%)$ or unknown origin $(16 \%)$ (Table 2). All isolates of unknown origin were probably made prior to the AIDS era. Therefore, we assume that they originated from non-AIDS patients. Both mating strains of $F$. neoformans $(\mathrm{NIH} 12=\mathrm{CBS} 6885$ and $\mathrm{NIH} 430=\mathrm{CBS}$ 6886) clustered here.

Some of the bands in cluster 3 isolates (= genotype 3 ) corresponded in size with bands in either cluster 1 or 2 (Fig. 2). Twenty-three and 21 bands agreed in size with bands of clusters 1 and 2, respectively. Thirty-two bands occurred in genotypes 1,2 and 3, and three bands were found to be unique for genotype 3. Genotype 3 represented isolates from Europe $(69 \%)$, North America $(15 \%)$ and from unknown origins $(15 \%)$. This distribution pattern is similar to that of genotype 2. Fortysix per cent of the isolates came from AIDS patients, 15 from non-AIDS patients, $23 \%$ from environmental sources, and $15 \%$ is from unknown origin (Table 2 ). Serotype D accounted for $57 \%$, serotype AD for $36 \%$ and serotype A isolates for 7\%. The type strain CBS 132 of C. neoformans was in this genotype.

\section{C. bacillisporus}

Cluster 4 (= genotype 4) contained serotype B isolates, including those from Eucalyptus, and occurred in Australia, the Americas, Africa, Asia and Southern Europe (Table 2). Forty-five per cent came from nonAIDS patients, $23 \%$ from animals, $29 \%$ from the environment, and $3 \%$ were of unknown origin. The two subclusters (4A and 4B, Figs 1 and 3) corresponded geographically with Africa/USA/Europe/Asia/S. America (cluster 4A) and with Australia/Asia/America (cluster 4B). Isolates from Spanish goats (Baró et al., 1998) occurred in cluster 4A together with a number of clinical isolates, and one isolate from Eucalyptus debris from a Californian zoo. The type strain RV 20186 (= CBS 6289) of C. neoformans var. gattii belonged here. Most of the Eucalyptus isolates from Australia and the USA formed a well-supported cluster in genotype 4B, together with clinical isolates from India, Honduras and China.

All cluster 5 (= genotype 5$)$ isolates originated from the Americas, with $45 \%$ from clinical non-AIDS samples, $29 \%$ from the environment, and $23 \%$ from unknown 


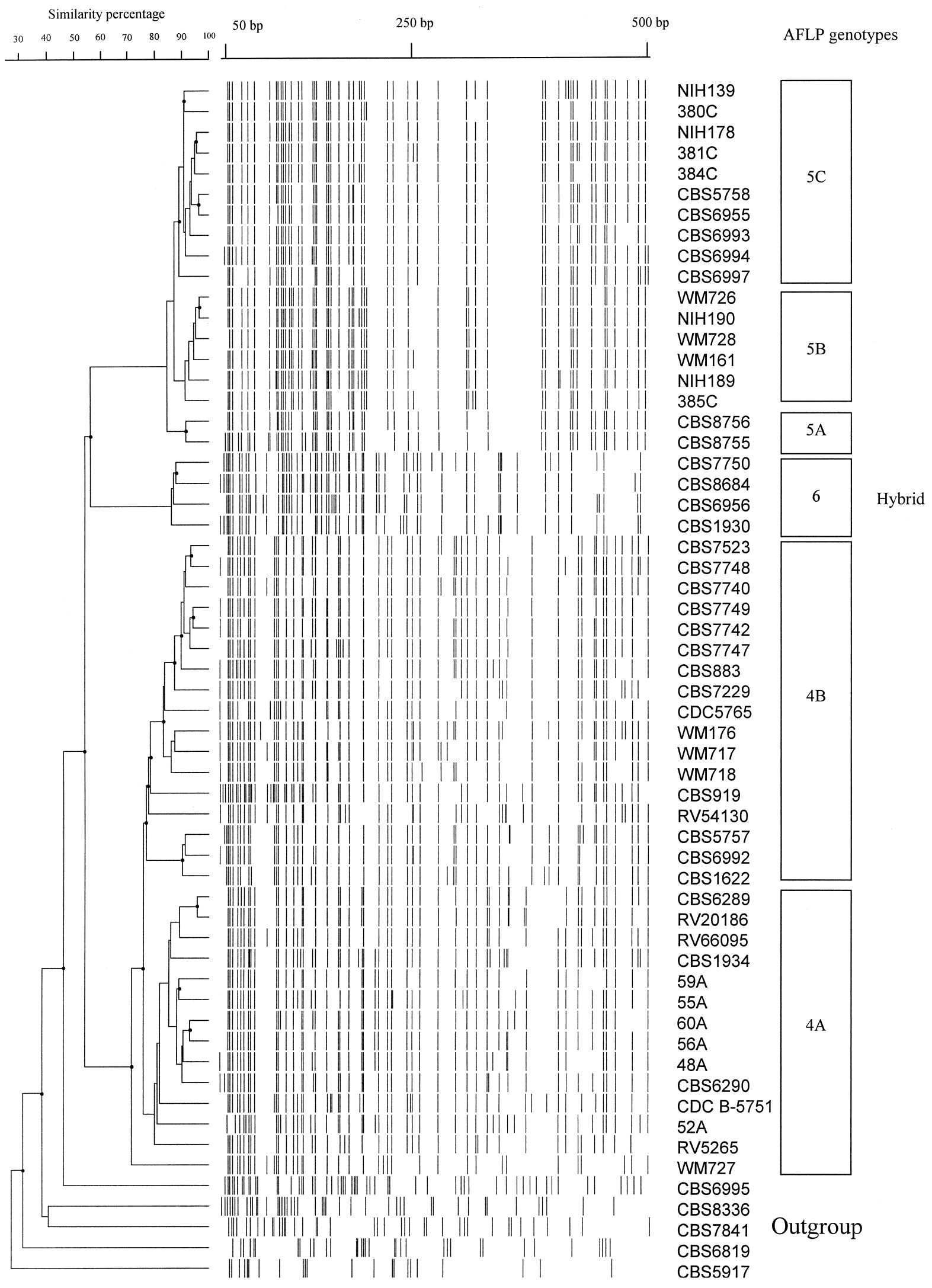

Fig. 3. Clustering of AFLP banding patterns of isolates of $C$. bacillisporus ( $=C$. neoformans var. gattii) by UPGMA. Dots indicate well-supported clusters (CCV $\geqslant 85 \%$ ). Note the hybrid pattern of genotype 6 , containing bands occurring in both genotypes 4 and 5. 

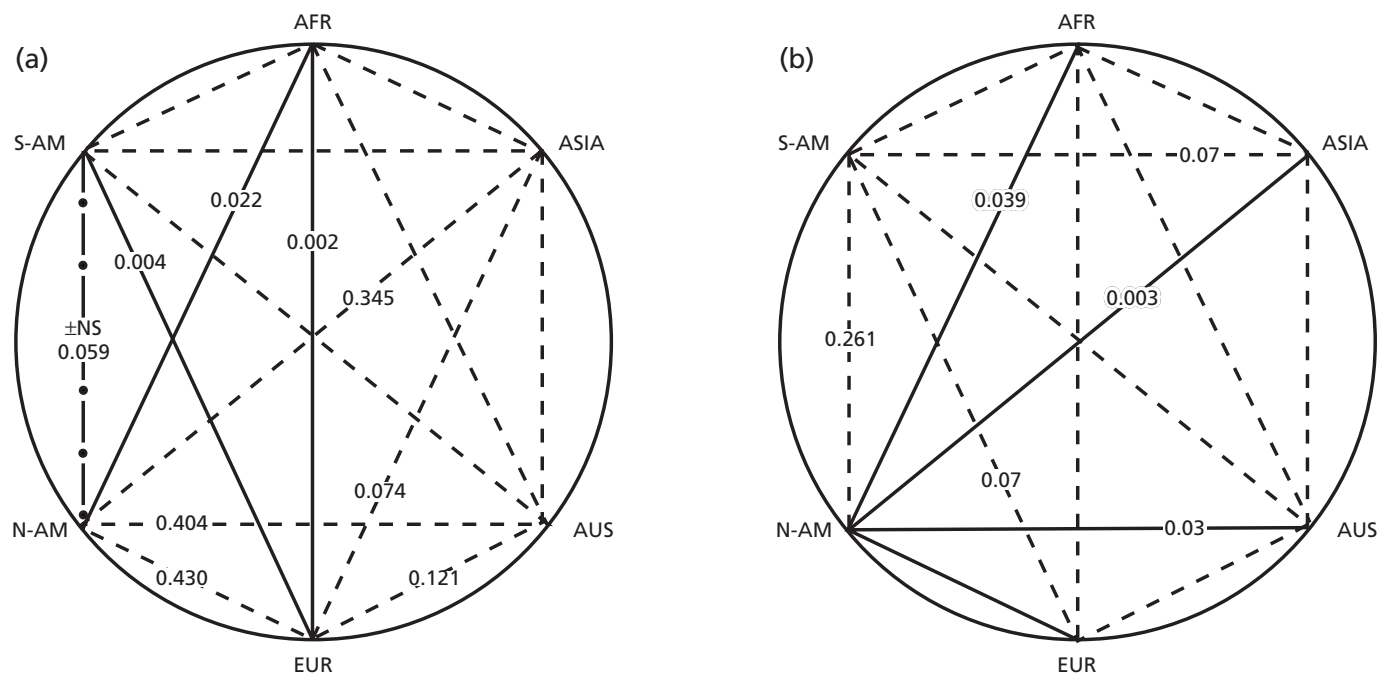

Fig. 4. Schematic representation of geographical distributions of AFLP genotypes of Cryptococcus neoformans (a) and C. bacillisporus (b). The numbers are exact $P$-values (chi-squared statistics). Full lines indicate statistically significant distributions (exact $P$-values $<0.05$ ); dashed lines indicate statistically non-significant distributions (exact $P$-values $>0.05$ ); dash-dotted lines indicate a near-significant (NS) distribution (exact $P$-value 0.059). In $C$. neoformans (a) the North American (N-AM) and European (EUR) populations differ from the African (AFR) and South American (S-AM) populations, with the latter being nearly significantly different from the North American population (exact $P$-value 0.059). The Asian and Australian (AUS) populations are not significantly different from the others. In C. bacillisporus (b) the North American population is significantly different from those of Africa, Asia, Australia and Europe, but not from the South Amrican one. The South American, African, Asian and European populations do not differ. Consequently the South American population has an intermediate position.

origin. None was AIDS related (Table 2). This cluster contained both serotype C $(67 \%)$ and serotype B $(33 \%)$ isolates. Three subclusters were apparent $(5 \mathrm{~A}-\mathrm{C})$ (Figs 1 and 3). The two environmental isolates from almond trees isolated in Colombia (Callejas et al., 1998) were in cluster $5 \mathrm{~A}$. Cluster $5 \mathrm{~B}$ contained serotype B isolates and one serotype $\mathrm{C}$ isolate, and originated from non-AIDS patients, Eucalyptus trees and related sources. All isolates from cluster 5C were serotype $\mathrm{C}$, and, as far as known, all came from non-AIDS patients. The type strain of F. bacillispora (NIH $191=$ CBS 6955) clustered here.

The sixth cluster (=genotype 6) contained only four serotype B isolates, CBS 1930, CBS 7750, CBS 8684 and CBS 6956, which originated from the Americas (Table 2). Two of the isolates were from environmental sources (a wasp nest, and Eucalyptus debris), one came from a sick goat, and the fourth was isolated from human sputum. This latter isolate was one of the mating strains of F. bacillispora (Kwon-Chung, 1998). The banding patterns of isolates belonging to this genotype were characterized by fewer AFLP bands, which in part agreed in size with bands from both genotypes 4 and 5 (Fig. 3). At least 12 bands corresponded in size with those of cluster 4, 11 agreed with bands of cluster 5, 14 were unique for this genotype, and 14 occurred in both genotypes 4 and 5 .

Mating strains of F. bacillispora clustered in all genotypes of the species, as follows: CBS 6992 (serotype B, genotype 4) $\times 6993$ (serotype C, genotype 5), and CBS 6956 (serotype B, genotype 6) ×6955 (serotype C, genotype 5).

\section{DISCUSSION}

\section{AFLP as a genotypic tool for the C. neoformans and C. bacillisporus species complex}

AFLP is a multilocus genotyping method combining universal applicability, high discriminative power and reproducibility for which only small amounts of DNA are required (Blears et al., 1998; Savelkoul et al., 1999; Vos et al., 1995). The method has been used for the genotyping of bacteria, plants, fungi and animals, and also for the construction of genetic maps (Blears et al., 1998; Breyne et al., 1999; de Barros Lopes et al., 1999; Janssen et al., 1996; Leissner et al., 1997; Otsen et al., 1996; Qi \& Lindhout, 1997; Savelkoul et al., 1999; Van der Lee et al., 1997). A large number of strainspecific genetic characters is available, because of the large number of bands generated using AFLP compared with RAPD and PCR fingerprinting (Boekhout et al., 1997; Meyer \& Mitchell, 1995; Meyer et al., 1993). This renders AFLP a sensitive tool allowing differentiation of genetically related strains.

To generalize the results of genotype studies, the collection of isolates studied should be representative of the genetic variation within the species. The collections of C. neoformans strains in culture collections are 
biased towards clinical isolates. However, if the ecological and geographical distribution of genotypes within a species is random, one may expect that the distributions of the respective genotypes would not widely differ from that of the species as a whole. With respect to geographical and serotype distribution this is not the case in C. neoformans, as can be seen in Table 2 and the chi-squared statistics applied. This strongly suggests that the genotypes differ in geographical distribution, which is clinically relevant as the pathogen may be acquired from the environment (Casadevall \& Perfect, 1998).

\section{The species problem in C. neoformans}

The recognition of species is an important, but controversial, problem in biology. Proper recognition of species is important because it may relate to differences in e.g. pathogenicity, resistance and virulence. In the $C$. neoformans complex the biological species concept has been used since the observation of matings (KwonChung, 1975, 1976). Initially, two distinct sexual species were distinguished within C. neoformans, namely $F$. neoformans and F. bacillispora. However, based on the observation of an interspecific mating between the strains CBS 6991 (F. neoformans, MATa, serotype D) and CBS 6956 (F. bacillispora, MAT $\alpha$, serotype B), which produced $30 \%$ viable basidiospores, the two species were considered as conspecific and both taxa were recognized as varieties (e.g. Kwon-Chung, 1998). Unfortunately, a genetic analysis of the basidiospores was not performed, and it has been noted that many interspecies crossings did not produce a fertile progeny. In addition, the sexual state has not been observed in nature. In time, growing evidence accumulated that the two varieties differ in many aspects, including phenotypic, biochemical, molecular, serological, ecological, epidemiological and clinical differences (Aulakh et al., 1981; Bennett et al., 1978; Boekhout \& Scorzetti, 1997; Boekhout et al., 1997; Cherniak \& Sundstrom, 1994; Dufait et al., 1987; Ellis \& Pfeiffer, 1992; Howard \& Kwon-Chung, 1995; Kwon-Chung et al., 1978, 1982a, 1987, 1988; Meyer \& Mitchell, 1995; Meyer et al., 1993; Mukaramangwa et al., 1995; Pfeiffer \& Ellis, 1993; Polacheck \& Kwon-Chung, 1980; Speed \& Dunt, 1995; Swinne, 1984; Wickes et al., 1994). Aulakh et al. (1981) observed only 55-63\% DNA relatedness between the varieties, and the chromosomal organization was found to be different as well (Boekhout et al., 1997; Wickes et al., 1994).

In our opinion, all these aspects weaken the suggested conspecificity of the taxa. Our AFLP results indicate the presence of two main genetic lineages within the pathogen, which seem to correspond with reproductively isolated groups of populations. The observation of hybrid genotypes within each lineage strongly suggests the presence of hybridization within the lineages, which therefore may be interpreted as biological species. Phylogenetic trees based on AFLP and the IGS of the rDNA (Diaz et al., 2001) strongly suggest that both these biological species are monophyletic as well. Therefore, the proposed species concept in the $C$. neoformans/C.bacillisporus complex is based on monophyletic and interbreeding groups of populations. It also supports the notion of Avise \& Wollenberg (1997) that the distinction between the biological species concept and the phylogenetic species concept, which is based on the concept of monophyly, is not always a sharp line.

We propose to name AFLP genotypes 1-3 as Filobasidiella neoformans Kwon-Chung with the anamorph Cryptococcus neoformans (Sanfelice) Vuillemin and AFLP genotypes 4-6 as Filobasidiella bacillispora Kwon-Chung with the anamorph Cryptococcus bacillisporus Kwon-Chung \& Bennett (=C. neoformans var. gattii Vanbreuseghem \& Takashio).

\section{C. neoformans}

The teleomorph F. neoformans and the anamorphs $C$. neoformans var. neoformans and C. neoformans var. grubii originated from AIDS and non-AIDS patients, veterinary sources, bird droppings, and occasionally from substrates such as fermenting fruit juice, drinking water, wood, soil and air (Casadevall \& Perfect, 1998; Levitz, 1991; Mitchell \& Perfect, 1995; SwinneDesgain, 1975; www.cbs.knaw.nl/search_ydb.html). All isolates obtained from AIDS patients belonged to this group. Recently, C. neoformans var. neoformans was also isolated from decaying wood of trees in Brazil (Lazera et al., 1993, 1996), and two of these isolates (CBS $8336,8337)$ occurred in cluster 1 . Trees may be the primary niche of the pathogen (Swinne, 1988). This is in agreement with the phylogenetic position in the order Tremellales (Fell et al., 2000) and the presence of the laccase enzyme system (Petter et al., 1996; Williamson, 1994). Because of the presence of haustorial branches in the Filobasidiella states, the hyphal state may occur as a mycoparasite (Bandoni, 1995).

Genotype 1 is identical with C. neoformans var. grubii (= serotype A). Incidentally, a serotype A isolate clustered in genotype 3 (isolate CBS 464). AFLP (this work) and IGS sequence data (Diaz et al., 2001) largely support the existence of C. neoformans var. grubii, but also showed that the resulting genotypic clusters do not entirely correspond with the serotype boundaries. This lack of concordancy can also be concluded from the URA5 sequence and CNRE-1 fingerprints presented by Franzot et al. (1998a), as in their data the serotype D isolate $\mathrm{J} 22$ clustered among serotype A isolates.

Global distribution of serotype A, which occurs mainly as the $\alpha$ mating type, may be related to the global expansion of one of its hosts, the common dove (Franzot et al., 1997). In this scenario, the original distribution of var. grubii was the same as that of this bird, namely North Africa and Europe. So far, no genetic differences have been observed between Old and New World isolates using a variety of molecular typing techniques such as RAPD, restriction analysis, electrophoretic karyotyping (PFGE), IGS sequences and AFLP patterns 
(Boekhout et al., 1997; Diaz et al., 2001; Meyer \& Mitchell, 1995; Varma et al., 1995). These observations were interpreted to support a clonal expansion model for this genotype, probably with the pigeon as vector (Franzot et al., 1997). However, the clonal expansion model seems to be contradicted by the observed interstrain variation in electrophoretic karyotypes, which are mitotically stable but meiotically unstable (Boekhout \& van Belkum, 1997; Boekhout et al., 1997), and the variation we observed in AFLP banding patterns. The observed geographical differences between genotypes 1 and 2 seem to contradict the 'pigeon as the primary ecological niche' hypothesis, as both genotypes commonly occur in bird excreta (Table 2).

The banding patterns of isolates in cluster $1 \mathrm{~A}$ differed from those of other cluster 1 isolates by the presence of a number of bands in common with genotype 2 . We presume that these isolates may represent hybrids between genotypes 1 and 2, but further genetic studies using additional markers are needed to confirm the genetic nature of these isolates.

Genotype 2 agrees with C. neoformans var. neoformans because it contains most serotype D isolates. However, a nomenclatural problem exists because the type strain of C. neoformans CBS 132 belongs to the hybrid genotype 3. Genotype 2 has a more limited geographical distribution than genotype 1. Its dominance in Europe $(57 \%)$ is in agreement with earlier observations on the dominance of serotype D isolates in Europe (Dromer et al., 1994, 1996). The environmental isolates mainly came from bird droppings, which were previously considered a source of pathogenic serotype D strains (Garçia-Hermoso et al., 1997).

The observed difference between the African versus the North American and European populations of $C$. neoformans seems clinically relevant, because of the severe problem of AIDS-related cryptococcosis in subSaharan Africa. Probable differences in virulence to AIDS patients between the three genotypes need further study in infection experiments using animal models, and analysis of virulence-related factors, such as capsule thickness, growth rates at $37^{\circ} \mathrm{C}$, melanin formation, protease activity and phospholipase activity (Franzot $e t$ al., 1998b; Fries \& Casadevall, 1998).

\section{C. bacillisporus (= C. neoformans var. gattii)}

This species, usually referred to as C. neoformans var. gattii, represents a distinct genetic lineage. The observed AFLP clustering of isolates of F. bacillispora was almost identical with that based on IGS sequences of the rDNA (Diaz et al., 2001), thus supporting the reliability of both methods for microbial typing. The naming of the taxon is complicated by the existence of older names which have priority, namely Cryptococcus hondurianus Castellani at the species level and Torulopsis neoformans var. sheppei Giordano at the variety level.

C. bacillisporus is limited to the tropics, the Southern hemisphere and Southern Europe, where it usually occurs in non-AIDS patients, animals, or saprobically associated with Eucalyptus and almond trees and bat guano (Ellis \& Pfeiffer, 1990, 1992; Howard \& KwonChung, 1995; Pfeiffer \& Ellis, 1993; Sorrell et al., 1996; Speed \& Dunt, 1995; www.cbs.knaw.nl/search ydb.html). The almost complete absence of this species in AIDS patients suggests a difference in virulence mechanisms as compared with C. neoformans (KwonChung et al., 1988; Speed \& Dunt, 1995).

Within this species three AFLP clusters occurred (numbered 4-6), thus suggesting a considerable genetic divergence. This divergence did not coincide with serotype boundaries, but rather followed geographical borders. Genotypes 5 and 6 occurred only in the Americas, and did not correspond with environmental versus clinical isolates. The North American population differed from the Asian, African, Australian and European populations. However, the South American population was not different from either of these groups of populations. Few isolates from our study were included in a recent published paper in which RAPD fingerprints and ITS sequences were used to investigate the geographical structure of the species (Imai et al., 2000). Our AFLP genotype 4 may coincide with their Asia-1 group, genotype 5 may be similar to their America-1 group, whereas genotype 6 may represent the America-2 group. However, more isolates from this study need to be investigated by AFLP to analyse the geographical relationships between the two types of data.

\section{Hybrid strains}

AFLP genotype 3 of C. neoformans contained a large number of bands corresponding in size with bands from either cluster 1 or cluster 2 (Fig. 2). Because of this mixed nature we postulate that genotype 3 represents a hybrid between AFLP genotypes 1 and 2. This hybrid, which formed a distinct cluster from another group of isolates representing a putative hybrid (genotype 1A), comprises about $9 \%$ of the C. neoformans isolates studied. The hybridization hypothesis is supported by the geographical distribution of the hybrid genotype, which is the same as that of one of the supposed hybridization partners (genotype 2). In our hybrid hypothesis, genetic material may be transferred between genotypes 1 (serotype A MAT $\alpha$ ) and 2 (serotype D MATa). Because genotype 3 occurs in relatively high proportion in AIDS patients $(46 \%)$ and in Europe $(69 \%)$, we assume that the hybridization events may contribute to the high incidence of serotype $\mathrm{D}$ isolates (either genotype 2 and 3 ) in AIDS-related cryptococcosis on this continent.

A number of isolates included in this study have been part of other genotyping studies as well. Using CNRE-1 fingerprints, serotype D isolate $\mathrm{J} 9$ (clustering in AFLP genotype 2) clustered with other serotype D isolates, including NIH 3501 (=CBS 6900) and NIH 3502 (= CBS 6902). However, serotype D isolate J22 (our hybrid AFLP genotype 3) clustered among serotype A isolates, rather distant from serotype D isolates (Franzot et al., 
1997, 1998a). When URA5 sequences were used, the isolate J22 clustered clearly distinct from serotype A isolates, and occurred with serotype D isolate B3501 (= CBS 6900), which in our AFLP analysis belonged to genotype 2. This lack of concordancy can be explained as a result of hybridization, as this may have caused separation of genetic markers. Genome sizes estimated from electrophoretic karyotypes ranged from 20 to $27 \mathrm{Mb}$ in the hybrid isolates, and from 15 to $19 \mathrm{Mb}$ in the parental isolates (Boekhout et al., 1997).

Genotype 6, representing about $8 \%$ of C. bacillisporus isolates, may represent a hybrid between isolates of genotypes 4 and 5 of this species. Although only four isolates of this genotype were studied, it is notable that only one of the hybrid strains came from clinical sources, as compared with about $45 \%$ and $50 \%$ for genotypes 4 and 5, respectively. [The recent discovery of another four isolates belonging to this hybrid genotype, which all came from trees in South America (M. Lazera \& T. Boekhout, unpublished) seems to support our observation that this genotype mainly occurs in the environment.] The estimated genome sizes for the putative hybrid isolates $(14-15 \mathrm{Mb})$ in C. bacillisporus are intermediate as compared with the parental isolates (12-18 Mb) (data from Boekhout et al., 1997).

As in C. neoformans, the geographical distribution of the putative hybrid of $C$. bacillisporus was limited to one of the hybridization partners, in this case genotype 5. Possibly the observed hybridization in C. bacillisporus can be explained by the introduction of genotype 4 isolates together with Eucalyptus trees into the Americas. This hypothesis is supported by the observed isolation of the North American population as compared with those from other parts of the world, and the intermediate position of the South American population. One hybrid isolate came from a Eucalyptus tree from California, and about $28 \%$ of the American genotype 5 isolates were isolated from Eucalyptus-related substrates. An alternative explanation is that both hybridization partners occur on Eucalyptus, and that genotype 5 and 6 isolates have not yet been found in other parts of the world.

The mechanism of hybridization in both species is not clear, and may be due to either sexual or parasexual processes. In the case of sexual hybridization in $C$. neoformans, we presume that the hybrids are due to hybridization between serotype A MAT $\alpha$ and serotype $\mathrm{D}$ MATa isolates, because the serotype A population is dominated by mating type $\alpha$ (Kwon-Chung \& Bennett, 1978). Heterozygosity was demonstrated to occur in putative hybrids by sequence analysis of PCR amplicons (Cogliati et al., 1999b), and diploid isolates were found in most cases to be serotype AD (Cogliati et al., 1999a; Tanaka et al., 1999). In a reanalysis of isozyme data generated by Brandt et al. (1993), Taylor et al. (1999) rejected the presence of recombination based on the assumption that the serotypes represented a single species. However, hybridization could not be rejected if serotypes $\mathrm{A}$ and $\mathrm{D}$ represented different species, and shuffling of alleles occurred only within a serotype. These authors suggested that serotypes of C. neoformans var. neoformans are undergoing cryptic speciation, and that recombination occurs within the A and D serotypes. The observed genetic divergence between serotypes A and D (Franzot et al., 1997, 1998a) was considered to support this hypothesis. In contrast, our results indicate that hybridization may occur between either the $\mathrm{A}$ and $\mathrm{D}$, or the $\mathrm{B}$ and $\mathrm{C}$ serotypes. The natural niche(s) of the fungus, be it trees, other fungi or another substrate, may be a good choice for investigating the occurrence of hybridization and the sexual states in nature.

Based on our AFLP results, as well as the literature discussed, we propose the presence of hybridization in C. neoformans and C. bacillisporus. Therefore, we favour the scenario that the fungus uses both (para)sexual and asexual reproduction strategies. Consequently, genetic material can be transferred between isolates of different genetic background, which may result in strains with an altered virulence and/or resistence to antifungal agents. Using subsequent clonal expansion, these strains may disseminate. Our hypothesis on the reproduction biology of the pathogen differs from the earlier proposed clonal reproduction of $C$. neoformans, which was based on linkage disequilibrium studies (Brandt et al., 1995, 1996), the observed concordance between molecular parameters (e.g. URA5 sequences and CNRE1 hybridization patterns) from geographically separated populations, and the dominance of a few genotypes in the population (Franzot et al., 1997). We propose a complex life cycle for the pathogen comprising both recombination and clonal expansion, and we suggest a role for the sexual Filobasidiella state in this process in vivo.

\section{Conclusions}

To summarize our data, we propose the following. (1) At least two pathogenic cryptococcal species exist, namely (a) C. neoformans with variety neoformans and variety grubii, and a sexual F. neoformans state, and (b) C. bacillisporus (synonym C. neoformans var. gattii) with the sexual state $F$. bacillispora. (2) In both species three AFLP genotypes occur, which differ in geographical and ecological behaviour. In each species one of these three genotypes has a hybrid nature. (3) Both sexual and asexual reproduction strategies are part of the reproduction biology of the pathogen. (4) Newly generated genotypes may disseminate clonally. (5) Serotype boundaries do not fully coincide with the genotypic groups, and therefore serotyping is not a reliable characteristic to differentiate infraspecific taxa.

\section{ACKNOWLEDGEMENTS}

We are indebted to Drs A. van Belkum (Rotterdam, The Netherlands), E. Castaneda (Bogotá, Colombia), F. Coenjaerts (Utrecht, The Netherlands), B. Fries and A. Casadevall (New York, NY, USA), S. Hamdan (Belo Horizonte, Brasil), K. J. Kwon-Chung (Bethesda, MD, USA), 
D. Howard (Los Angeles, CA, USA), J. Torres-Rodríguez (Barcelona, Spain) and D. Swinne (Antwerp, Belgium) for sending us cryptococcal isolates; O. Ronin (Institut Pasteur, Paris, France) contributed by serotyping, and E. de Vries (CBS, Utrecht, The Netherlands) by maintaining the strain collection and lyophilization prior to DNA isolation. Two anonymous reviewers considerably improved the manuscript by making useful suggestions.

\section{REFERENCES}

Aulakh, H. S., Straus, S. E. \& Kwon-Chung, K. J. (1981). Genetic relatedness of Filobasidiella neoformans (Cryptococcus neoformans) and Filobasidiella bacillispora (Cryptococcus bacillisporus) as determined by deoxyribonucleic acid base composition and sequence homology studies. Int J Syst Bacteriol 31, 97-103.

Avise, J. C. \& Wollenberg, K. (1997). Phylogenetics and the origin of species. Proc Natl Acad Sci US A 94, 7748-7755.

Bandoni, R. J. (1995). Dimorphic heterobasidiomycetes: taxonomy and parasitism. Stud Mycol 38, 13-27.

Baró, T., Torres-Rodríguez, J. M., Hermoso de Mendoza, M., Norera, Y. \& Alía, C. (1998). First identification of autochthonous Cryptococcus neoformans var. gattii isolated from goats with predominantly severe pulmonary disease in Spain. J Clin Microbiol 36, 458-461.

de Barros Lopes, M., Rainieri, S., Henschke, P. A. \& Langridge, P. (1999). AFLP fingerprinting for analysis of yeast genetic variation. Int J Syst Bacteriol 49, 915-924.

Bennett, J. E., Kwon-Chung, K. J. \& Theodore, T. S. (1978). Biochemical differences between serotypes of Cryptococcus neoformans. Sabouraudia 16, 167-174.

Blears, M. J., De Grandis, S. A., Lee, H. \& Trevors, J. T. (1998). Amplified fragment length polymorphism (AFLP): a review of the procedure and its applications. J Ind Microbiol Biotechnol 21, 99-114.

Boekhout, T. \& van Belkum, A. (1997). Variability of karyotypes and RAPD types in genetically related strains of Cryptococcus neoformans. Curr Genet 32, 203-208.

Boekhout, T. \& Scorzetti, G. (1997). Differential killer toxin sensitivity patterns of varieties of Cryptococcus neoformans. J Med Vet Mycol 35, 147-149.

Boekhout, T., van Belkum, A., Leenders, A. C. A. P., Verbrugh, H. A., Mukamurangwa, P., Swinne, D. \& Scheffers, W. A. (1997). Molecular typing of Cryptococcus neoformans: taxonomic and epidemiological aspects. Int J Syst Bacteriol 47, 432-442.

Brandt, M. E., Bragg, S. L. \& Pinner, R. W. (1993). Multilocus enzyme typing of Cryptococcus neoformans. J Clin Microbiol 31, 2819-2823.

Brandt, M. E., Hutwagner, L. C., Pinner, R. W. \& the Cryptococcal Disease Active Surveillance Group (1995). Comparison of multilocus enzyme electrophoresis and random amplification of polymorphic DNA analysis for molecular subtyping of Cryptococcus neoformans. J Clin Microbiol 33, 1890-1895.

Brandt, M. E., Hutwagner, L. C., Klug, L. A. \& 9 other authors (1996). Molecular subtype distribution of Cryptococcus neoformans in four areas of the United States. J Clin Microbiol 34, 912-917.

Breyne, P., Rombaut, D., Van Gysel, A., Van Montagu, M. \& Gerats, T. (1999). AFLP analysis of genetic diversity within and between Arabidopsis thaliana ecotypes. Mol Gen Genet 261, 627-634.

Callejas, A., Ordoñez, N., Rodríguez, M. C. \& Castañeda, E. (1998).
First isolation of Cryptococcus neoformans var. gattii, serotype C, from the environment in Colombia. Med Mycol 36, 341-344.

Casadevall, A. \& Perfect, J. R. (1998). Cryptococcus neoformans, pp. 1-541. Washington, DC: American Society for Microbiology. Cherniak, R. \& Sundstrom, J. B. (1994). Polysaccharide antigens of the capsule of Cryptococcus neoformans. Infect Immun 62, 1507-1512.

Cogliati, M., Allaria, M., Tortorano, A. M., Liberi, G. \& Viviani, M. A. (1999a). Occurrence of diploidy correlated to PCR-fingerprinting patterns of Cryptococcus neoformans var. neoformans. In Programme and Abstracts, 4th International Conference on Cryptococcus and Cryptococcosis, September 1999, p. 137. London: Royal Society.

Cogliati, M., Allaria, M., Tortorano, A. M. \& Viviani, M. A. (1999b). Sequence analysis and evaluation of heterozygosity in PCR fingerprinting patterns of Cryptococcus neoformans var. neoformans. In Programme and Abstracts, 4th International Conference on Cryptococcus and Cryptococcosis, p. 110. London: Royal Society.

Diaz, M. R., Boekhout, T., Theelen, B. \& Fell, J. W. (2001). Molecular sequence analyses of the intergenic spacer (IGS) associated with rDNA of the two varieties of the pathogenic yeast, Cryptococcus neoformans. Syst Appl Microbiol (in press). Dromer, F., Guého, E., Ronin, O. \& Dupont, B. (1993). Serotyping of Cryptococcus neoformans by using a monoclonal antibody specific for capsular polysaccharide. J Clin Microbiol 31, 359-363.

Dromer, F., Varma, A., Ronin, O., Mathoulin, S. \& Dupont, B. (1994). Molecular typing of Cryptococcus neoformans serotype D clinical isolates. J Clin Microbiol 32, 2364-2371.

Dromer, F., Mathoulin, S., Dupont, B., Laporte, A. \& the French Cryptococcosis Study Group (1996). Epidemiology of cryptococcosis in France: a 9-year survey (1985-1993). Clin Infect Dis 23, 82-90.

Dufait, R., Velho, R. \& De Vroey, C. (1987). Rapid identification of the two varieties of Cryptococcus neoformans by D-proline assimilation. Mykosen 30, 483.

Ellis, D. H. \& Pfeiffer, T. J. (1990). Ecology, life cycle, and infectious propagule of Cryptococcus neoformans. Lancet 336, 923-925.

Ellis, D. \& Pfeiffer, T. (1992). The ecology of Cryptococcus neoformans. Eur J Epidemiol 8, 321-325.

Fell, J. W., Boekhout, T., Fonseca, A., Scorzetti, G. \& StatzellTallman, A. (2000). Biodiversity and systematics of basidiomycetous yeasts as determined by large subunit rDNA D1/D2 domain sequence analysis. Int J Syst Evol Microbiol 50, 1351-1371.

Franzot, S. P., Hamdan, J. S., Currie, B. P. \& Casadevall, A. (1997). Molecular epidemiology of Cryptococcus neoformans in Brazil and the United States: evidence for both local genetic differences and a global clonal population structure. J Clin Microbiol 35, 2243-2251.

Franzot, S. P., Fries, B. C., Cleare, W. \& Casadevall, A. (1998a). Genetic relationship between Cryptococcus neoformans var. neoformans strains of serotypes A and D. J Clin Microbiol 36, 2200-2204.

Franzot, S. P., Mukherjee, J., Cherniak, R., Chen, L.-C., Hamdan, J. S. \& Casadevall, A. (1998b). Microevolution of standard strain of Cryptococcus neoformans resulting in differences in virulence and other phenotypes. Infect Immun 66, 89-97.

Franzot, S. P., Salkin, I. F. \& Casadevall, A. (1999). Cryptococcus neoformans var. grubii: separate varietal status for Cryptococcus neoformans serotype A isolates. J Clin Microbiol 37, 838-840. 
Fries, B. C. \& Casadevall, A. (1998). Serial isolates of Cryptococcus neoformans from patients with AIDS differ in virulence for mice. J Infect Dis 178, 1761-1766.

Garçia-Hermoso, D., Mathoulin-Pélissier, S., Couprie, B., Ronin, O., Dupont, B. \& Dromer, F. (1997). DNA typing suggests pigeon dropping as a source of pathogenic Cryptococcus neoformans serotype D. J Clin Microbiol 35, 2683-2685.

Howard, D. H. \& Kwon-Chung, K. J. (1995). Zoopathogenic basidiomycetous yeasts. Stud Mycol 38, 59-66.

Ikeda, R., Shinoda, T., Fukazawa, Y. \& Kaufman, L. (1982). Antigenic characterization of Cryptococcus neoformans serotypes and its application to serotyping of clinical isolates. J Clin Microbiol 16, 22-29.

Imai, T., Watanabe, K., Mikami, Y., Tanaka, R., Nishimura, K. Miyaji, M., Poonwan, N. \& Branchini, M. L. M. (2000). Geographic grouping of Cryptococcus neoformans var. gattii by random amplified polymorphic DNA fingerprint patterns and ITS sequence divergence. Clin Lab 46, 345-354.

Janssen, P., Coopman, R., Huys, G., Swings, J., Bleeker, M., Vos, P., Zabeau, M. \& Kersters, K. (1996). Evaluation of the DNA fingerprinting method AFLP as a new tool in bacterial taxonomy. Microbiology 142, 1881-1893.

Kovacs, J. A., Kovacs, A. A., Polis, M. \& 12 other authors (1985). Cryptococcosis in the acquired immonudeficiency syndrome. Ann Intern Med 103, 533-538.

Kwon-Chung, K. J. (1975). A new genus, Filobasidiella, the perfect state of Cryptococcus neoformans. Mycologia 67, 1197-1200.

Kwon-Chung, K. J. (1976). A new species of Filobasidiella, the sexual state of Cryptococcus neoformans B and C serotypes. Mycologia 68, 942-946.

Kwon-Chung, K. J. (1998). Filobasidiella Kwon-Chung. In The Yeasts, a Taxonomic Study, 4th edn, pp. 656-662. Edited by C. P. Kurtzman \& J. W. Fell. Amsterdam: Elsevier.

Kwon-Chung, K. J. \& Bennett, J. E. (1978). Distribution of $\alpha$ and a mating types of Cryptococcus neoformans among natural and clinical isolates. Am J Epidemiol 108, 337-340.

Kwon-Chung, K. J. \& Bennett, J. E. (1984). Epidemiologic differences between the two varieties of Cryptococcus neoformans. Am J Epidemiol 120, 123-130.

Kwon-Chung, K. J., Bennett, J. E. \& Theodore, T. S. (1978) Cryptococcus bacillisporus sp. nov.: serotype B-C of Cryptococcus neoformans. Int J Syst Bacteriol 28, 616-620.

Kwon-Chung, K. J., Polacheck, I. \& Bennett, J. E. (1982a). Improved diagnostic medium for separation of Cryptococcus neoformans var. neoformans (serotypes A and D) and Cryptococcus neoformans var. gattii (serotypes $\mathrm{B}$ and C). J Clin Microbiol 15, 535-537.

Kwon-Chung, K. J., Bennett, J. E. \& Rhodes, J. C. (1982b). Taxonomic studies on Filobasidiella species and their anamorphs. Antonie Leeuwenhoek 48, 25-38.

Kwon-Chung, K. J., Wickes, B. L., Booth, J. L., Vishniac, H. S. \& Bennett, J. E. (1987). Urease inhibition by EDTA in the two varieties of Cryptococcus neoformans. Infect Immun $\mathbf{5 5}$, 1751-1754.

Kwon-Chung, K. J., Varma, A. K. \& Howard, D. H. (1988). Ecology and epidemiology of Cryptococcus neoformans: a recent study of isolates in the United States. In Proceedings X Congress ISHAM, June 27-July 1, 1988, pp. 107-112. Edited by J. M. TorresRodríguez. Barcelona: Prous Science.

Lazera, M. S., Wanke, B. \& Nishikawa, N. M. (1993). Isolation of both varieties of Cryptococcus neoformans from saprophytic sources in the city of Rio de Janeiro, Brazil. J Med Vet Mycol 31, $449-454$.

Lazera, M. S., Pires, F. D. A., Camillo-Coura, L., Nishikawa, M. M., Bezerra, C. C. F., Trilles, L. \& Wanke, B. (1996). Natural habitat of Cryptococcus neoformans var. neoformans in decaying wood forming hollows in living trees. J Med Vet Mycol 34, 127-131.

Leissner, C. E. W., Niessen, M. L. \& Vogel, R. F. (1997). Use of AFLP technique for the identification and discrimination of Fusarium graminearum. Cereal Res Commun 25, 555-556.

Levitz, S. M. (1991). The ecology of Cryptococcus neoformans and the epidemiology of cryptococcosis. Rev Infect Dis 13, 1163-1169.

Meyer, W. \& Mitchell, T. G. (1995). Polymerase chain reaction fingerprinting in fungi using single primers specific to minisatellites and simple repetitive DNA sequences: strain variation in Cryptococcus neoformans. Electrophoresis 16, 1648-1656.

Meyer, W., Mitchell, T. G., Freedman, E. Z. \& Vilgalys, R. (1993). Hybridization probes for conventional DNA fingerprinting used as single primers in the polymerase chain reaction to distinguish strains of Cryptococcus neoformans. J Clin Microbiol 31, 2274-2280.

Mitchell, T. G. \& Perfect, J. R. (1995). Cryptococcosis in the era of AIDS - 100 years after the discovery of Cryptococcus neoformans. Clin Microbiol Rev 8, 515-548.

Mukaramangwa, P., Raes Wuytack, C. \& De Vroey, C. (1995). Cryptococcus neoformans var. gattii can be separated from var. neoformans by its ability to assimilate D-tryptophan. J Med Vet Mycol 33, 419-420.

O’Donnell, K., Cigelnik, E., Weber, N. S. \& Trappe, J. M. (1997). Phylogenetic relationships among ascomycetous truffles and the true and false morels inferred from $18 \mathrm{~S}$ and $28 \mathrm{~S}$ rDNA sequence analysis. Mycologia 89, 48-65.

Otsen, M., den Bieman, M., Kuiper, M. T., Pravenec, M., Kren, V., Kurtz, T. W., Jacob, H. J., Lankhorst, A. \& van Zutphen, B. F. (1996). Use of AFLP markers for gene mapping and OTL detection in the rat. Genomics 37, 289-294.

Petter, R., Varma, A., Boekhout, T., Salas, S., Davis, B. \& KwonChung, K. J. (1996). Molecular divergence of the virulence factors of Filobasidiella neoformans found in other heterobasidiomycetous yeasts. In Programme and Abstracts, 3 rd International Conference on Cryptococcus and Cryptococcosis, pp. 136-138. Paris: Institut Pasteur.

Pfeiffer, T. J. \& Ellis, D. H. (1993). Serotypes of Australian environmental and clinical isolates of Cryptococcus neoformans. J Med Vet Mycol 31, 401-404.

Polacheck, I. \& Kwon-Chung, K. J. (1980). Creatinine metabolism in Cryptococcus neoformans and Cryptococcus bacillisporus. J Bacteriol 142, 15-20.

Qi, X. \& Lindhout, P. (1997). Development of AFLP markers in barley. Mol Gen Genet 254, 330-336.

Savelkoul, P. H. M., Aarts, H. J. M., de Haas, J., Dijkshoorn, L., Duim, B., Otsen, M., Rademaker, J. L. W., Schouls, L. \& Lenstra, J. A. (1999). Amplified-fragment length polymorphism analysis: the state of the art. J Clin Microbiol 37, 3083-3091.

Schupbach, C. W., Wheeler, C. E., Briggaman, R. A., Warner, N. A. \& Kanof, E. P. (1976). Cutaneous manifestations of dissiminated cryptococcosis. Arch Dermatol 112, 1734-1740.

Sorrell, T. C., Brownlee, A. G., Ruma, P., Malik, R., Pfeiffer, T. J. \& Ellis, D. H. (1996). Natural environmental sources of Cryptococcus neoformans var. gattii. J Clin Microbiol 34, 1261-1263.

Speed, B. \& Dunt, D. (1995). Clinical and host differences between 
infections with the two varieties of Cryptococcus neoformans. Clin Infect Dis 21, 28-34.

Swinne, D. (1984). Study of Cryptococcus neoformans varieties. Mykosen 27, 137-141.

Swinne, D. (1988). Ecology of Cryptococcus neoformans and epidemiology of cryptococcosis in the old world. In Proceedings X Congress ISHAM, June 27-July 1, 1988, pp. 113-119. Edited by J. M. Torres-Rodríguez. Barcelona: Prous Science.

Swinne-Desgain, D. (1975). Cryptococcus neoformans of saprophytic origin. Sabouraudia 13, 303-308.

Tanaka, R., Nishimura, K. \& Miyaji, M. (1999). Ploidy of serotype AD strains of Cryptococcus neoformans. Nippon Ishinkin Gakkai Zasshi 40, 31-34.

Taylor, J. W., Geiser, D. M., Burt, A. \& Koufopanou, V. (1999). The evolutionary biology and population genetics underlying fungal strain typing. Clin Microbiol Rev 12, 126-147.

Van der Lee, T., de Witte, I., Drenth, A., Alfonso, C. \& Govers, F. (1997). AFLP linkage map of the oomycete Phytophthora infestans. Fungal Genet Biol 21, 278-291.
Varma, A., Swinne, D., Staib, F., Bennett, J. E. \& Kwon-Chung, K. J. (1995). Diversity of DNA fingerprints in Cryptococcus neoformans. J Clin Microbiol 33, 1807-1814.

Vos, P., Hogers, R., Bleeker, M. \& 8 other authors (1995). AFLP: a new technique for DNA fingerprinting. Nucleic Acids Res 23, 4407-4414.

Wickes, B. L., Moore, T. D. E. \& Kwon-Chung, K. J. (1994). Comparison of the electrophoretic karyotypes and chromosomal location of ten genes in the two varieties of Cryptococcus neoformans. Microbiology 140, 543-550.

Williamson, P. R. (1994). Biochemical and molecular characterization of the diphenol oxidase of Cryptococcus neoformans: identification as a laccase. J Bacteriol 176, 656-664.

Zabeau, M. \& Vos, P. (1993). Selective restriction fragment amplification: a general method for DNA fingerprinting. European Patent Office Publication 0534858 A1.

Received 11 July 2000; revised 13 November 2000; accepted 2 January 2001. 